\title{
Review
}

\section{The Role of Energy Flux in Weight Management}

\author{
Clemens Drenowatz ${ }^{1 *}$, Klaus Greier ${ }^{2,3}$ \\ ${ }^{1}$ Division of Physical Education, University of Education Upper Austria, Kaplanhofstraße 40, 4020 Linz, AUSTRIA \\ ${ }^{2}$ Division of Physical Education, Private Educational College - Edith Stein, Stams, AUSTRIA \\ ${ }^{3}$ Institute for Sports Science, Leopold-Franzens-University Innsbruck, AUSTRIA
}

\author{
History:

\section{Keywords:} \\ Energy expenditure \\ Energy intake \\ Obesity \\ Physical activity
}

Article Information

Received: October 25, 2017

Accepted: November 21, 2017

Published: December 5, 2017

\begin{abstract}
Excess body weight has been identified as one of the leading threats to public health. In addition to health concerns at the individual level, the increased medical costs put a significant burden on the health care system. Even though an imbalance between energy intake and energy expenditure is ultimately responsible for changes in body weight and body composition such a simple opposition does not reflect the complex interaction of various contributors to energy balance.

The limited understanding of the regulation of energy balance is also reflected by rising obesity levels, despite considerable efforts. In addition to energy balance, energy flux, which represents the rate of energy intake and energy expenditure, has been suggested to play an important role in the regulation of energy balance. Particularly a higher energy flux has been associated with a better matching of energy intake and energy expenditure resulting in stable body weight. While a high energy flux has been traditionally attributed to increased levels of physical activity it should be considered that increased body weight also affects energy expenditure and accordingly energy flux.

In fact, total daily energy expenditure, and accordingly energy flux, does not differ between people in industrialized countries, living a predominantly sedentary lifestyle and people following a traditional lifestyle, characterized by high physical activity even though there are significant differences in body weight and body composition. It can, therefore, be argued that energy flux, rather than energy balance is a physiologically regulated entity. In this situation body weight and physical activity levels work in opposition to maintain a constant energy flux and weight gain would be a means to maintain a high energy flux with a sedentary lifestyle.
\end{abstract}

\section{INTRODUCTION}

With more than 2 billion people (roughly $30 \%$ of the world population) being considered overweight or obese [1], excess body weight is considered one of the leading health problems in the 21st century [2]. The association between excess body weight and increased risk for cardiovascular and metabolic disease risk along with orthopedic problems, impaired pulmonary function, depressive symptoms and overall quality of life has been well documented $[3,4]$. In addition to the impact on individual health, weight-related health problems put a significant burden on the health care

${ }^{*}$ Correspondence: Clemens Drenowatz

Division of Physical Education, University of Education Upper Austria, Kaplanhofstraße 40, 4020 Linz, AUSTRIA

E-mail address: clemens.drenowatz@ph-ooe.at system as they have been estimated to make up $10 \%$ of all healthcare expenditures [5]. Particularly obesity has been associated with decreased productivity, increased number of doctor's visits and hospital stays [6,7], resulting in 36\% higher costs in both inpatient and outpatient spending along with $77 \%$ higher costs for medication compared to normal weight individuals [8].

The rising prevalence of obesity [1], despite considerable efforts, also reflects the limited understanding of the complex interaction of cultural, psychosocial, biochemical, metabolic and genetic factors contributing to the regulation of energy balance. Based on the laws of thermodynamics energy intake (EI) and energy expenditure (EE) need to match over time in order to maintain body weight. Such a simple opposition of EI and EE, however, ignores the complex interaction of physiological and environmental constraints within the concept of energy balance [9]. Body weight should not be viewed as a simple outcome based on the interaction of 


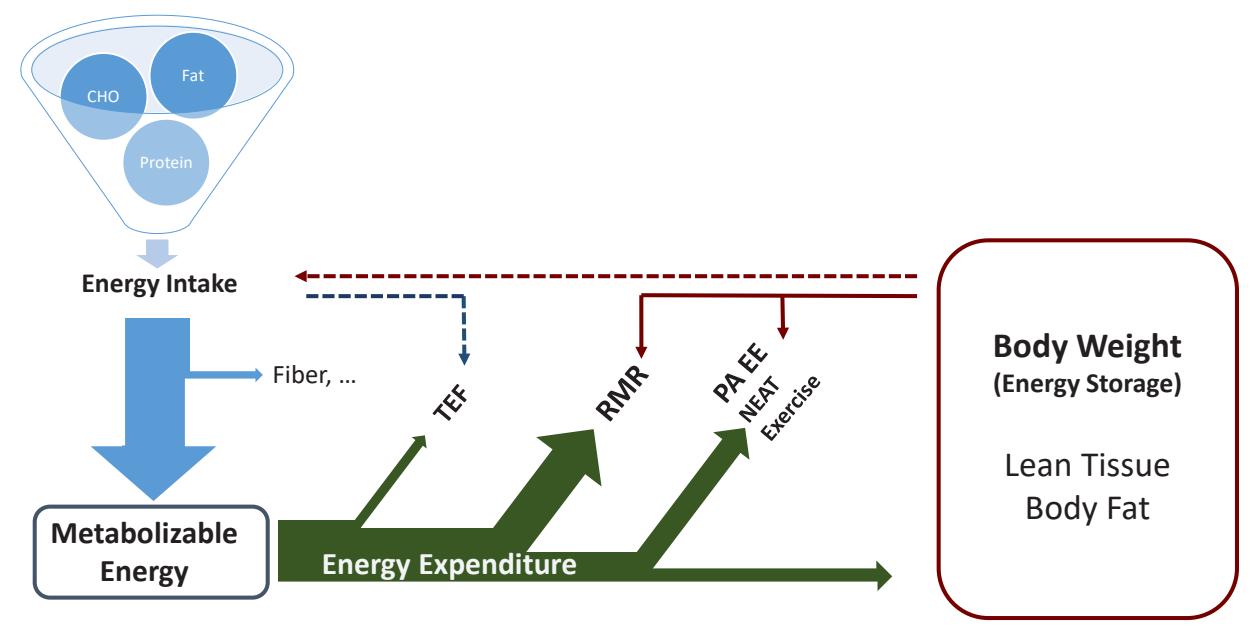

Figure 1. Interaction of energy intake, energy expenditure and body weight/energy storage.

EI and EE but rather as an additional component within the energy balance system (Figure 1). Alterations in body composition, for example, are associated with changes in resting metabolic rate and energy requirements for various movements [10]. Further, body composition has been suggested to affect dietary intake [11]. An additional problem in the accurate matching of EI and EE is that EI occurs in episodical events while EE is a continuous process. Accordingly, the human body is almost constantly in energy imbalance - an energy surplus following a meal and an energy deficit during various activities without any food consumption, including sleep [12]. There is also considerable variability in daily EI and EE with little association between EI and EE on a daily basis. Even in people who are considered to be in energy balance (i.e. maintenance of body weight), it has been shown that EE and EI do not match on a daily basis [12-14]. Small differences between EI and EE, however, can have significant effects on body weight in the longterm [15]. In fact a commonly observed annual weight gain between 0.5 and $1 \mathrm{~kg}$ per year has been associated with an energy surplus of only 50 to $100 \mathrm{kcal} /$ day [16]. These small differences, however, may be difficult to detect by various physiological systems and it has been argued that macronutrient intake rather than total EI are regulated [17]. Social constraints potentially affect energy balance as well and may override physiological processes as people tend to put on weight in a non-linear fashion with a more pronounced weight gain during the weekend compared to weekdays as well as during certain times of the year (i.e. winter holiday season) [18-20]. Accordingly, data from pharmacological weight loss trials lead to question a body weight control system [21].

\section{The Role of Energy Flux in Weight Management}

Even though an imbalance between EI and EE is ultimately responsible for weight change, the rate of EI and EE along with alterations in body weight, which is also referred to as energy flux [22], has been suggested to play an important role in weight management as well. Theoretically, ener- gy balance can be achieved at various levels of energy flux (i.e. low EE matched by low EI or high EE with high EI) but a higher energy flux has generally been associated with a better matching of EI and EE $[23,24]$. These studies attributed a higher energy flux to high levels of physical activity (PA). Alterations in body weight, however, affect energy expenditure and accordingly energy flux as well [10]. Using doubly labelled water it has been shown that total daily energy expenditure (TDEE) does not differ between populations pursuing a traditional lifestyle, characterized by high physical activity and those living a typical western lifestyle, characterized by predominantly sedentary habits $[25,26]$ (Figure 2). There was also no difference in TDEE between populations living in low, middle or highly, developed countries [27], indicating a similar energy flux. A sedentary lifestyle, generally observed in industrialized countries, however, was associated with significantly higher body weight [25-27].

Similarly, there was a comparable EI between men with

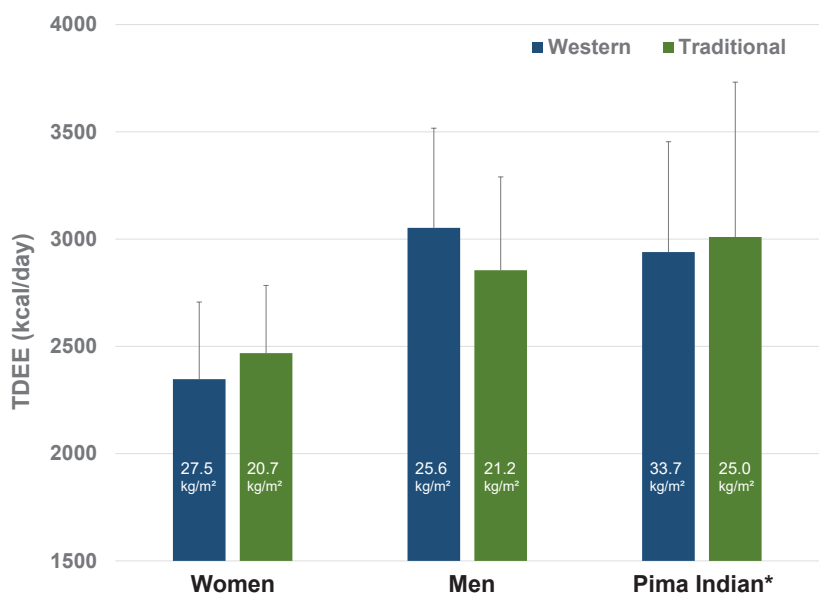

Figure 2. Total daily energy expenditure (TDEE) measured by DLW in different populations.

Based on Pontzer et al. [25] and Esparza et al. [26]. Values are Means with SD and average BMI.

${ }^{*}$ Mixed sample of similar heritage 
sedentary occupations (i.e. clerks) and those engaging in heavy work (i.e. blacksmiths, cutters, carriers), despite considerable differences in PA and body weight [28]. A recent study also did not show any change in average EE or EI over a period of 2 years in participants who experienced a significant weight change [29]. While these participants certainly experienced alterations in EE and EI in order to induce weight change, these alterations may have been small in nature and, therefore, difficult to detect. There were, however, significant behavioral changes with an increase in PA in participants who lost weight and a decrease in PA in those who gained weight, allowing participants to maintain their $\mathrm{EE}$ and EI despite alterations in body weight. Accordingly it may be speculated that energy flux, rather than energy balance, is a regulated entity and that human beings use different strategies to achieve a certain energy flux; either sufficient PA or increased body weight.

The importance of a high energy flux in order to maintain energy balance may be a result of the development of human physiology under circumstances of high PA demands and accordingly high energy flux [30]. In fact, participation in PA has been considered a biologically normal condition in pre-industrial eras $[31,32]$. At the same time, there was a limited supply of food in the past, which emphasized the need to minimize energy output and potentially facilitated the development of a homeostatically controlled TDEE in order to ensure survival [28]. As a result, an upper threshold for TDEE and energy flux would have been determined based on the interaction of food availability and PA (required to obtain food and ensure survival). Data from animal and human studies in various environments support the theory of a physiologically constrained energy flux [33]. For example, there were no differences in EE or EI between monozygotic twins who differed in PA levels and body composition $[34,35]$. Similarly, there was no difference in TDEE between members of an Indian tribe living a predominantly

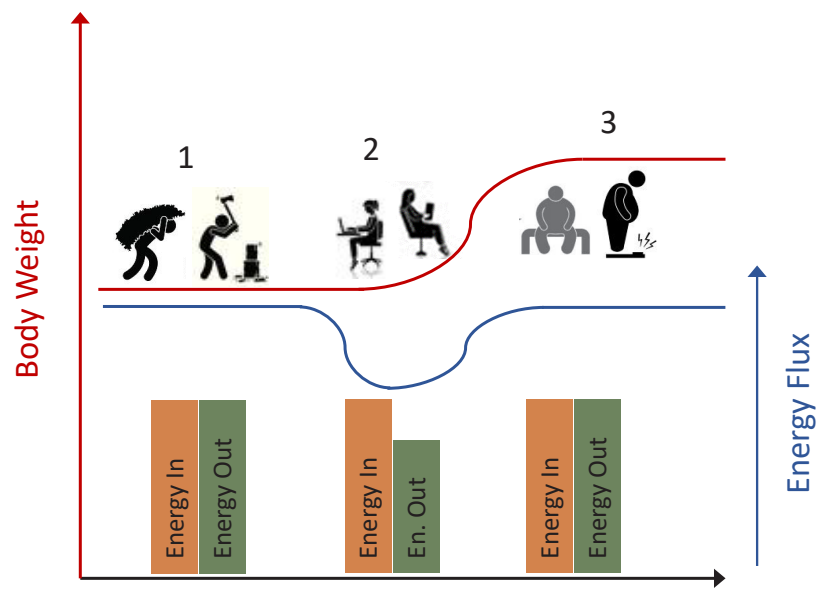

Figure 3. Maintenance of Energy Flux at different activity levels

1) high PA at healthy body weight; 2) reduction in energy flux due to lower PA along with imbalance between energy intake and energy expenditure; 3 ) increased body weight to achieve higher energy flux with low PA sedentary lifestyle with accompanied increased body weight in a U.S. reservation and those following a traditional lifestyle, characterized by high PA and lower body weight in Mexico [26]. It has also been shown that EI does not change in response to long-term alterations in PA while overeating has not been associated with alterations in PA [36]. An insecure food supply may have contributed to a predisposition of overeating and storage of excess calories in the form of fat during times when excess food was available in order to prepare for times with sparse food availability [37]. In the modern environment foods, however, are readily and constantly available while high amounts of PA are no longer required, resulting in a mismatch between physiology and environment as human beings have developed biological adaptations for hunger but not for overconsumption [38,39]. Given this situation, increased body weight can be viewed as a normal and predictable biological adaptation to a sedentary lifestyle in order to achieve a homeostatic state at a physiologically predetermined energy flux [40] (Figure 3).

\section{Practical Implications}

Given the importance of PA in weight management and the fact that the majority of people in industrialized countries have sedentary occupations, a critical question would be how to incorporate a sufficient level of PA in our daily lives. Even though active travel has been promoted as viable option, the contribution of active travel to TDEE has been considered negligible [51] and Ohkawara et al. argued that the general population is unlikely to achieve the necessary volume of locomotor activities to affect TDEE [52]. While activities such as walking have beneficial effects on chronic disease risk these activities had limited effects on energy expenditure and body weight [53]. In order to affect body weight and body composition, activities of higher intensities appear to be necessary [54-57], which most likely warrant a more structured approach, such as exercise.

Traditional aerobic exercise interventions, however, have been of limited success particularly in overweight and obese participants [58]. This has, in part, been attributed to compensatory reductions in habitual PA, which would have minimized exercise-induced alterations in TDEE [36,59]. Resistance exercise, on the other hand, has been associated with increased functional capacity that allows participants to engage in additional activities outside the exercise intervention [60-62]. Resistance exercise has also been associated with an increase in fat oxidation [63], which could have positive effects on body composition. Another approach, particularly in children, could be a focus on motor development as increased motor competence facilitates the engagement in various physical activities [64]. Overall, intervention strategies should focus on facilitating participation in various activities, including habitual PA as this may enhance the chances that participants continue with an activity lifestyle beyond the intervention period and, therefore, provide more sustainable results. 


\section{SUMMARY}

Given the limited success in addressing the obesity epidemic, the consideration of a stable energy flux could provide a valuable framework for the development of strategies addressing the obesity epidemic. If energy flux is considered a regulated entity, its regulation must occur via complex interactions among key components of energy balance with changes in body weight and PA representing critical opposite forces in the regulation of energy flux. In such a scenario weight gain would be simply a means to maintain energy flux at low PA levels. It remains to be determined, however, whether alterations in PA precede changes in body weight or whether it is a response to weight gain or weight loss. A hypothesized individually predetermined energy flux also takes a more encompassing approach towards the regulation of body weight including a gene-environment interaction [15]. An inter-individual variability in energy flux could help to explain the differences in body weight between people living in a similar environment as not everybody exposed to an obesogenic environment experiences excess weight gain. It can be speculated that people who are predisposed to a higher energy flux may actually be at increased risk for excess body weight in the modern environment as they can easily achieve a high EI while high PA requires considerable conscious efforts. These people may also have developed more efficient strategies in storing excess calories. Those who have a lower predetermined energy flux, on the other hand, may consume less calories and/or are less prone to store excess calories even in the current environment and, therefore, could maintain a healthy body weight with lower PA.

Considering energy flux as a regulated entity further explains why people who are currently obese would not be able to maintain weight loss by dietary restriction alone. Weight loss, due to dietary restriction ultimately results in a lower energy flux, which would trigger compensatory effects, such as an increase in appetite followed by an increase in body weight; a situation that usually occurs with this type of weight loss intervention $[65,66]$. A reduced EI in order to loose weight with an accompanying increase in PA, on the other hand, would allow individuals to maintain a lower body weight when EI returns to initial levels resulting in an energy flux level that is not significantly different from that seen prior to weight loss. Even though more research is needed to clarify the role of energy flux and potential physiological constraints associated with the regulation of energy flux it emphasizes the critical role of PA in long-term weight management.

\section{Conflicts of interest}

$\mathrm{CD}$ received funding from the Coca Cola Company. No funding has been received for the preparation of this article.

\section{REFERENCES}

1. NCD Risk Factor Collaboration (NCD-RisC). Trends in adult body-mass index in 200 countries from 1975 to 2014: a pooled analysis of 1698 population-based measurement studies with 19.2 million participants. Lancet. 2016; 387(10026):1377-96.

2. WHO. World health report 2002: Reducing risk - promoting healthy life. Geneva, Switzerland. WHO Press. 2002.

3. Reilly JJ, Methven E, McDowell ZC, et al. Health consequences of obesity. Arch Dis Child 2003; 88(9):748-52.

4. Lobstein T, Baur L, Uauy R, TaskForce IIO. Obesity in children and young people: a crisis in public health. Obes Rev. 2004; 5(Suppl 1):4-104.

5. Finkelstein EA, Trogdon JG, Cohen JW, Dietz W. Annual medical spending attributable to obesity: payer-and service-specific estimates. Health Aff (Millwood). 2009; 28(5):w822-31.

6. Park MH, Falconer C, Viner RM, Kinra S. The impact of childhood obesity on morbidity and mortality in adulthood: a systematic review. Obes Rev. 2012; 13(11):9851000 .

7. Thompson D, Brown J, Nichols G, Elmer P, Oster G. Body Mass Index and future healthcare costs: A retrospective cohort study. Obesity Res. 2001; 9(3):210-18.

8. Sturm R. The effects of obesity, smoking, and drinking on medical problems and costs. Health Aff (Millwood). 2002; 21(2):245-53.

9. Speakman JR. Obesity: the integrated roles of environment and genetics. J Nutr. 2004; 134(8 Suppl) :2090S-105S.

10. Hand G, Blair S. Energy flux and its role in obesity and metabolic disease. US Endocrinology. 2014; 10(1):5964 .

11. Klok MD, Jakobsdottir S, Drent ML. The role of leptin and ghrelin in the regulation of food intake and body weight in humans: a review. Obes Rev. 2007; 8(1):21-34.

12. Hall KD, Heymsfield SB, Kemnitz JW, Klein S, Schoeller DA, Speakman JR. Energy balance and its components: implications for body weight regulation. Am J Clin Nutr. 2012; 95(4):989-94.

13. Westerterp KR. Physical activity, food intake, and body weight regulation: insights from doubly labeled water studies. Nutr Rev. 2010; 68(3):148-54.

14. Schoeller DA, Thomas D. Energy balance and body composition. World Rev Nutr Diet. 2015; 111:13-8.

15. Speakman JR, Levitsky DA, Allison DB, et al. Set points, settling points and some alternative models: theoretical options to understand how genes and environments combine to regulate body adiposity. Dis Model Mech. 2011; 4(6):733-45.

16. Hill JO. Understanding and addressing the epidemic of obesity: an energy balance perspective. Endocr Rev. 2006; 27(7):750-61.

17. Pi-Sunyer FX, Aronne LJ, Heshmati HM, Devin J, Rosenstock J, Group R-NAS. Effect of rimonabant, a cannabinoid-1 receptor blocker, on weight and cardiometabolic risk factors in overweight or obese patients: RIO-North America: a randomized controlled trial. 
JAMA. 2006; 295(7):761-75.

18. Orsama AL, Mattila E, Ermes M, van Gils M, Wansink B, Korhonen I. Weight rhythms: weight increases during weekends and decreases during weekdays. Obes Facts. 2014; 7(1):36-47.

19. Racette SB, Weiss EP, Schechtman KB, et al. Influence of weekend lifestyle patterns on body weight. Obesity (Silver Spring). 2008; 16(8):1826-30.

20. Yanovski JA, Yanovski SZ, Sovik KN, Nguyen TT, O’Neil PM, Sebring NG. A prospective study of holiday weight gain. N Engl J Med. 2000; 342(12):861-7.

21. Müller MJ, Bosy-Westphal A, Heymsfield SB. Is there evidence for a set point that regulates human body weight? F1000 Med Rep. 2010; 2:59

22. Hill JO, Wyatt HR, Peters JC. Energy balance and obesity. Circulation. 2012; 126(1):126-32.

23. Blundell JE, Gibbons C, Caudwell P, Finlayson G, Hopkins M. Appetite control and energy balance: impact of exercise. Obes Rev. 2015; 16 Suppl 1:67-76.

24. Shook RP, Hand GA, Drenowatz C, et al. Low levels of physical activity are associated with dysregulation of energy intake and fat mass gain over 1 year. Am J Clin Nutr. 2015; 102(6):1332-8.

25. Pontzer H, Raichlen DA, Wood BM, Mabulla AZ, Racette SB, Marlowe FW. Hunter-gatherer energetics and human obesity. PLoS One. 2012; 7(7):e40503.

26. Esparza J, Fox C, Harper IT, et al. Daily energy expenditure in Mexican and USA Pima indians: low physical activity as a possible cause of obesity. Int J Obes Relat Metab Disord. 2000; 24(1):55-9.

27. Dugas LR, Harders R, Merrill S, et al. Energy expenditure in adults living in developing compared with industrialized countries: a meta-analysis of doubly labeled water studies. Am J Clin Nutr. 2011; 93(2):427-41.

28. Mayer J, Roy P, Mitra KP. Relation between caloric intake, body weight, and physical work: studies in an industrial male population in West Bengal. Am J Clin Nutr. 1956; 4(2):169-75.

29. Drenowatz C, Hill JO, Peters JC, Soriano-Maldonado A, Blair SN. The association of change in physical activity and body weight in the regulation of total energy expenditure. Eur J Clin Nutr. 2017; 71(3):377-82.

30. Leonard W. Size counts: Evolutionary perspectives on physical activity and body size from early hominids to modern humans. J Phys Act Health. 2010; 7(Suppl 3):S284-S98

31. Booth FW, Lees SJ. Physically active subjects should be the control group. Med Sci Sports Exerc. 2006; 38(3):405-6.

32. Hawley JA, Holloszy JO. Exercise: it's the real thing! Nutr Rev. 2009; 67(3):172-8.

33. Pontzer H. Constrained Total Energy Expenditure and the Evolutionary Biology of Energy Balance. Exerc Sport Sci Rev. 2015; 43(3):110-6.

34. Doornweerd S, IJzerman RG, van der Eijk L, et al. Physical activity and dietary intake in BMI discordant identical twins. Obesity (Silver Spring). 2016; 24(6):1349-55.
35. Pietiläinen $\mathrm{KH}$, Korkeila $\mathrm{M}$, Bogl LH, et al. Inaccuracies in food and physical activity diaries of obese subjects: complementary evidence from doubly labeled water and co-twin assessments. Int J Obes (Lond). 2010; 34(3):437-45.

36. Drenowatz C. Reciprocal Compensation to Changes in Dietary Intake and Energy Expenditure within the Concept of Energy Balance. Adv Nutr. 2015; 6(5):592-9.

37. Chakravarthy M, Booth F. Eating, exercise and "thrifty" genotypes: connecting the dots toward an evolutionary understanding of modern chronic diseases. J Appl Physiol. 2004; 96:3-10.

38. Peters JC, Wyatt HR, Donahoo WT, Hill JO. From instinct to intellect: the challenge of maintaining healthy weight in the modern world. Obes Rev. 2002;3(2):69-74.

39. Heitmann BL, Westerterp KR, Loos RJ, et al. Obesity: lessons from evolution and the environment. Obes Rev 2012; 13(10):910-22.

40. Chaput JP, Klingenberg L, Rosenkilde M, Gilbert JA, Tremblay A, Sjödin A. Physical activity plays an important role in body weight regulation. J Obes. 2011; 2011: 360257.

41. Swinburn BA, Sacks G, Lo SK, et al. Estimating the changes in energy flux that characterize the rise in obesity prevalence. Am J Clin Nutr. 2009; 89(6):1723-8.

42. Westerterp KR, Speakman JR. Physical activity energy expenditure has not declined since the 1980s and matches energy expenditures of wild mammals. Int J Obes (Lond). 2008; 32(8):1256-63.

43. Briefel RR, Johnson CL. Secular trends in dietary intake in the United States. Annu Rev Nutr. 2004; 24:401-31.

44. USDA Agricultural Research Service. Nutrient intakes from food: mean amounts consumed per individual, one day, 2005-06. Secondary Nutrient intakes from food: mean amounts consumed per individual, one day, 2005-06 2008. www.ars.usda.gov/ba/bhnrc/fsrg (Accessed June 25, 2017).

45. Binkley JK, Eales J, Jekanowski M. The relation between dietary change and rising US obesity. Int J Obes Relat Metab Disord. 2000; 24(8):1032-9.

46. Hill J, Levine J, Saris W. Energy expenditure and physical activity. In: Bray G, Bouchard C, eds. Handbook of Obesity. 2nd ed. Boca Raton, FL: CRC Press, 2003; 63154 .

47. DeLany JP, Kelley DE, Hames KC, Jakicic JM, Goodpaster $\mathrm{BH}$. High energy expenditure masks low physical activity in obesity. Int J Obes (Lond). 2013; 37(7):100611.

48. Katz DL. Competing dietary claims for weight loss: finding the forest through truculent trees. Annu Rev Public Health. 2005; 26:61-88.

49. Kruger J, Blanck HM, Gillespie C. Dietary practices, dining out behavior, and physical activity correlates of weight loss maintenance. Prev Chronic Dis. 2008; 5(1):A11

50. Catenacci VA, Ogden LG, Stuht J, et al. Physical activity patterns in the National Weight Control Registry. Obe- 
sity (Silver Spring). 2008; 16(1):153-61.

51. Csizmadi I, Lo Siou G, Friedenreich CM, Owen N, Robson PJ. Hours spent and energy expended in physical activity domains: results from the Tomorrow Project cohort in Alberta, Canada. Int J Behav Nutr Phys Act. 2011; 8:110.

52. Ohkawara K, Ishikawa-Takata K, Park JH, Tabata I, Tanaka S. How much locomotive activity is needed for an active physical activity level: analysis of total step counts. BMC Res Notes. 2011; 4:512.

53. Ford ES, Caspersen CJ. Sedentary behaviour and cardiovascular disease: a review of prospective studies. Int J Epidemiol. 2012; 41(5):1338-53.

54. Bernstein MS, Costanza MC, Morabia A. Association of physical activity intensity levels with overweight and obesity in a population-based sample of adults. Prev Med. 2004; 38(1):94-104.

55. Boutcher SH. High-intensity intermittent exercise and fat loss. J Obes 2011; 2011:868305.

56. Trapp EG, Chisholm DJ, Freund J, Boutcher SH. The effects of high-intensity intermittent exercise training on fat loss and fasting insulin levels of young women. Int J Obes (Lond). 2008; 32(4):684-91.

57. Wareham NJ, van Sluijs EM, Ekelund U. Physical activity and obesity prevention: a review of the current evidence. Proc Nutr Soc. 2005; 64(2):229-47.

58. Dhurandhar EJ, Kaiser KA, Dawson JA, Alcorn AS, Keating KD, Allison DB. Predicting adult weight change in the real world: a systematic review and meta-analysis accounting for compensatory changes in energy intake or expenditure. Int J Obes (Lond). 2015; 39(8):1181-87.

59. Westerterp KR. Pattern and intensity of physical activity. Nature. 2001; 410(6828):539.

60. Drenowatz C, Grieve GL, DeMello MM. Change in energy expenditure and physical activity in response to aerobic and resistance exercise programs. Springerplus. 2015; 4:798.

61. Hunter GR, Wetzstein CJ, Fields DA, Brown A, Bamman MM. Resistance training increases total energy expenditure and free-living physical activity in older adults. J Appl Physiol (1985). 2000; 89(3):977-84.

62. Strasser B, Schobersberger W. Evidence for resistance training as a treatment therapy in obesity. J Obes. 2011; 2011:482564.

63. Kirk EP, Donnelly JE, Smith BK, et al. Minimal resistance training improves daily energy expenditure and fat oxidation. Med Sci Sports Exerc. 2009; 41(5):1122-9.

64. Drenowatz C. A focus on motor competence as alternative strategy for weight management. J Obes Chron Dis. 2017; 1(2):31-38.

65. Ochner CN, Barrios DM, Lee CD, Pi-Sunyer FX. Biological mechanisms that promote weight regain following weight loss in obese humans. Physiol Behav. 2013; 120:106-13.

66. Melby CL, Paris HL, Foright RM, Peth J. Attenuating the Biologic Drive for Weight Regain Following Weight Loss: Must What Goes Down Always Go Back Up? Nutrients 2017; 9(5):468. 